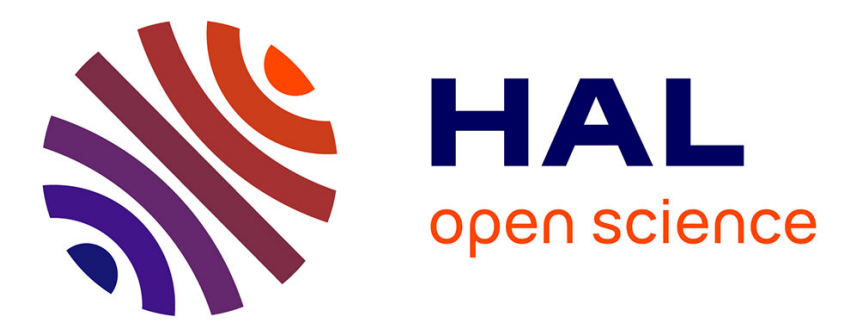

\title{
Ultrasonic Studies of Textured Superconducting Bi2Sr2CaCu2O8+y in Magnetic Fields
}

Q. A. Wang, D. Almond, G. Saunders, S. Palmer, C B Lim, K. Goretta

\section{To cite this version:}

Q. A. Wang, D. Almond, G. Saunders, S. Palmer, C B Lim, et al.. Ultrasonic Studies of Textured Superconducting Bi2Sr2CaCu2O8+y in Magnetic Fields. Journal de Physique IV Proceedings, 1996, 06 (C8), pp.C8-481-C8-484. 10.1051/jp4:19968104 . jpa-00254532

\section{HAL Id: jpa-00254532 https://hal.science/jpa-00254532}

Submitted on 1 Jan 1996

HAL is a multi-disciplinary open access archive for the deposit and dissemination of scientific research documents, whether they are published or not. The documents may come from teaching and research institutions in France or abroad, or from public or private research centers.
L'archive ouverte pluridisciplinaire HAL, est destinée au dépôt et à la diffusion de documents scientifiques de niveau recherche, publiés ou non, émanant des établissements d'enseignement et de recherche français ou étrangers, des laboratoires publics ou privés. 


\title{
Ultrasonic Studies of Textured Superconducting $\mathrm{Bi}_{2} \mathrm{Sr}_{2} \mathrm{CaCu}_{2} \mathrm{O}_{8+y}$ in Magnetic Fields
}

\author{
Q.Wang, D.P. Almond, G.A. Saunders, S.B. Palmer*, C.M. Lim* and K.C. Goretta** \\ Schools of Physics and Materials Science, University of Bath, Bath, BA2 7AY, U.K. \\ * Department of Physics, University of Warwick, Coventry, CV4 7AL, U.K. \\ ** Energy Technology Division, Argonne National Laboratory, Argonne, IL 60439, U.S.A.
}

\begin{abstract}
Measurements have been made of ultrasonic shear wave attenuation and sound velocity in highly textured polycrystalline samples of $\mathrm{Bi}_{2} \mathrm{Sr}_{2} \mathrm{CaCu}_{2} \mathrm{O}_{8+\mathrm{y}}$ in magnetic fields up to 9 telsa and at temperatures down to $4.2 \mathrm{~K}$. Magnetic field dependent attenuation peaks and velocity enhancements were found that are in good agreement with theoretical predictions based on the assumptions of the thermally assisted flux flow model of the mixed state. A pinning activation energy of $\sim 160 \mathrm{~K}$ was deduced from the ultrasonic data. Pinning energy showed little evidence of dependence upon magnetic field magnitude or orientation. The flux-line lattice was found to be pinned fully at lowest temperatures.
\end{abstract}

\section{INTRODUCTION}

The development of a comprehensive understanding of the mixed state in high temperature superconductors is widely considered to be a key issue, essential for the successful application of these materials. Much of the complexity of the mixed state is caused by relatively weak flux-line pinning mechanisms, that lead to thermally activated flux creep and particularly low irreversibility temperatures. A consequence is that otherwise attractive materials, such as $\mathrm{Bi}_{2} \mathrm{Sr}_{2} \mathrm{CaCu}_{2} \mathrm{O}_{8+y}$, can only be used for high current and magnetic field applications at very low temperatures.

Common techniques employed to investigate the mixed state involve the measurement of: A.C. susceptibility, magnetisation or magnetoresistance. In the first two of these, the flux-line-lattice (FLL) is excited with fields applied to the surface of a sample and true bulk behaviour may be obscured by FLL pinning effects caused by impurities, inhomogeneities and lattice defects associated with the surface. Magnetoresistance measurements may also be dominated by surface currents that will be affected by such extrinsic features. An alternative approach is to excite the crystal lattice that contains the pinning sites and to make an assessment of their coupling to the FLL based on measurements of elastic properties. Ultrasonic wave propagation techniques employ very small amplitudes of vibration, typically $<10 \mathrm{~nm}$, and they have the merit of probing the bulk of a sample and of being quite unaffected by the characteristics of the surface. The propagation of ultrasonic waves through a superconductor in the mixed state was analysed by Pankert [1] and subsequently investigated experimentally using ceramic samples of Bi 2223 [2]. Hanaguri et al [3] completed a detailed study of the anisotropy of pinning in a single crystal of $\mathrm{La}_{1.85} \mathrm{Sr}_{0.15} \mathrm{CuO}_{4}$. They presented a complex picture in which pinning showed substantial dependence upon magnetic field amplitude and orientation and in which the FLL was incompletely pinned at lowest temperatures. This type of ultrasonic study has been restricted to single crystal $\mathrm{La}_{1.85} \mathrm{Sr}_{0.15} \mathrm{CuO}_{4}$ because it has not proved possible to grow the large single crystals $(5 \times 5 \times 5 \mathrm{~mm})$ of other high temperature superconductor types that are required for ultrasonic measurements.

In previous work [4] we have argued that, in the absence of large single crystals, highly textured, sinter forged, samples of $\mathrm{Bi}_{2} \mathrm{Sr}_{2} \mathrm{CaCl}_{2} \mathrm{O}_{8+y}$ can be treated as quasi-crystals that provide a fair indication of 
the anisotropy in the elastic properties. It is clear that highly textured polycrystalline material provides a route to commercial applications and this adds to the importance of gaining a full understanding of this type of material.

\section{THEORETICAL BACKGROUND}

The Pankert model [1] of ultrasonic wave propagation through a superconductor in the mixed state makes the assumptions that the crystal lattice and the flux-line-lattice are coupled by flux line pinning and that the extent of this pinning can be accounted for in terms of the thermally assisted flux flow model (TAFF) [5]. At very low temperatures and if there are sufficient pinning centres, the FLL is pinned fully and the elastic strains associated with a propagating ultrasonic wave produce identical strains in the FLL. This straining of the FLL produces additional elastic stiffness components and corresponding increases in ultrasound velocity. For the additional compressional, shear and tilt elastic moduli components, $\Delta \mathrm{c}_{11}{ }^{\mathrm{f}}, \Delta \mathrm{c}_{66}{ }_{\mathrm{f}}^{\mathrm{f}}$ and $\Delta \mathrm{c}_{44}{ }^{\mathrm{f}}$ :

$$
\Delta \mathrm{c}_{66}{ }^{\mathrm{f}}<\Delta \mathrm{c}_{11}{ }^{\mathrm{f}}=\Delta \mathrm{c}_{44}{ }_{\mathrm{f}}=\mathrm{B}^{2} / \mu_{0}
$$

where $B$ is the applied magnetic flux density and $\mu_{0}$ is the permeability of free space [1].

The period of time that a flux line remains pinned is assumed to be limited by thermally activated depinning mechanisms that are a function of a pinning activation energy and temperature. Consequently, the FLL will appear to be pinned when interrogated by a dynamic probe if the depinning rate is substantially less than the probe frequency and it will appear unpinned where the depinning rate substantially exceeds the probe frequency. In practice the depinning rate falls as temperature is reduced and an enhancement in sound velocity is found at low temperatures. This is corresponds to conventional anelastic behaviour and it is accompanied by a peak in ultrasonic attenuation.

\section{EXPERIMENTAL DETAILS}

The samples used in this work were prepared at the Argonne National Laboratory. The preparation and characteristics of one of the two samples (sample 1) and other experimental details were described before [4]. Briefly, the sample was a $95 \%$ theoretical density sinter forged, highly textured sample of $\mathrm{Bi}_{2} \mathrm{Sr}_{2} \mathrm{CaCu}_{2} \mathrm{O}_{8+\mathrm{y}}$ having dimensions of roughly $5 \times 5 \times 3 \mathrm{~mm}$. It was cut and polished to produce faces perpendicular $(1 \times 5 \mathrm{~mm})$ and parallel $(5 \times 5 \mathrm{~mm})$ to the crystallite's c-axes, to facilitate ultrasonic wave propagation parallel to the c-axes and in the $a-b$ plane. The second sample (sample 2) was produced in the same fashion for studies of propagation along the c-axis alone and took the form of an $a-b$ plane orientated slab $10 \times 11 \mathrm{~mm}$ with a c-axis thickness of $3.73 \mathrm{~mm}$. The samples were studied with the magnetic fields applied: (a) along the $c$-axis and (b) parallel to the $a-b$ plane. For the c-axis magnetisation direction, the FLL will be pinned by extrinsic features (lattice defects, impurities, grain boundaries) whereas for a-b plane magnetisation, it has been suggested [6] that pinning is intrinsic and attributable to the normal layers separating the $\mathrm{Bi}_{2} \mathrm{Sr}_{2} \mathrm{CaCu}_{2} \mathrm{O}_{8-\mathrm{y}} \mathrm{CuO}_{2}$ conduction planes. Following Hanaguri et al [3]: the terminology CA mode is used here to indicate magnetic field (FLL orientation) and ultrasonic shear wave propagation along the $\mathrm{c}$-axis direction, with shear displacement direction in the $\mathrm{a}-\mathrm{b}$ plane; for shear wave propagation and magnetic field aligned with the $\mathrm{a}-\mathrm{b}$ plane, $\mathrm{AC}$ mode indicates shear displacement aligned with the $\mathrm{c}-$ axis and the $\mathrm{AB}$ mode, shear displacement set perpendicular to the $c$-axis, in the $a-b$ plane.

\section{RESULTS}

Typical $13 \mathrm{MHz}$ ultrasound velocity and attenuation data, Figure 1, show the predicted anelastic phenomena. However, the quality of the velocity data was found to be much greater than that of the attenuation so only the analysis of velocity data is presented here. The FLL components of elastic modulus for (a) CA mode (sample 2) and (b) AC mode (sample 1), shown in Figure 2, were obtained by converting the velocity changes produced by the applied magnetic fields to changes in elastic modulus. The fitted lines through the data are non-linear least squares fits of the Pankert [1] expressions, assuming the temperature range to be sufficiently far below Tc to fit the pinning potential as a temperature independent parameter. Data for all of the modes were analysed in this way. 

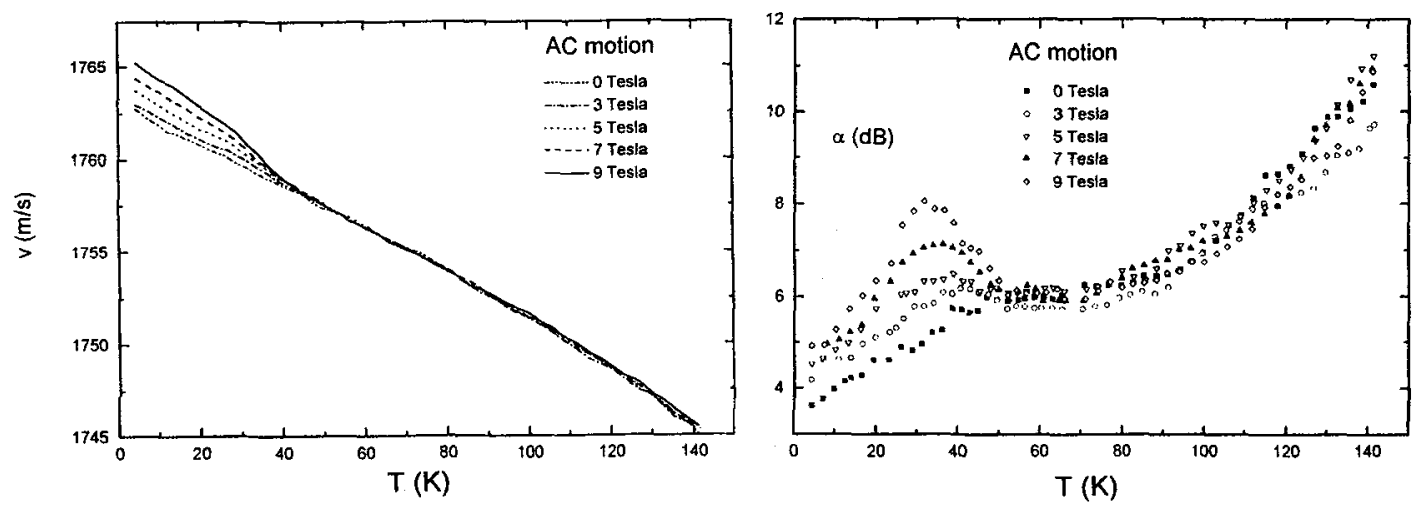

Figure 1. Temperature dependences of (a) sound velocity and (b) attenuation showing AC mode interaction with the FLLs produced in $\mathrm{Bi}_{2} \mathrm{Sr}_{2} \mathrm{CaCl}_{2} \mathrm{O}_{8+y}$ by the magnetic fields indicated.
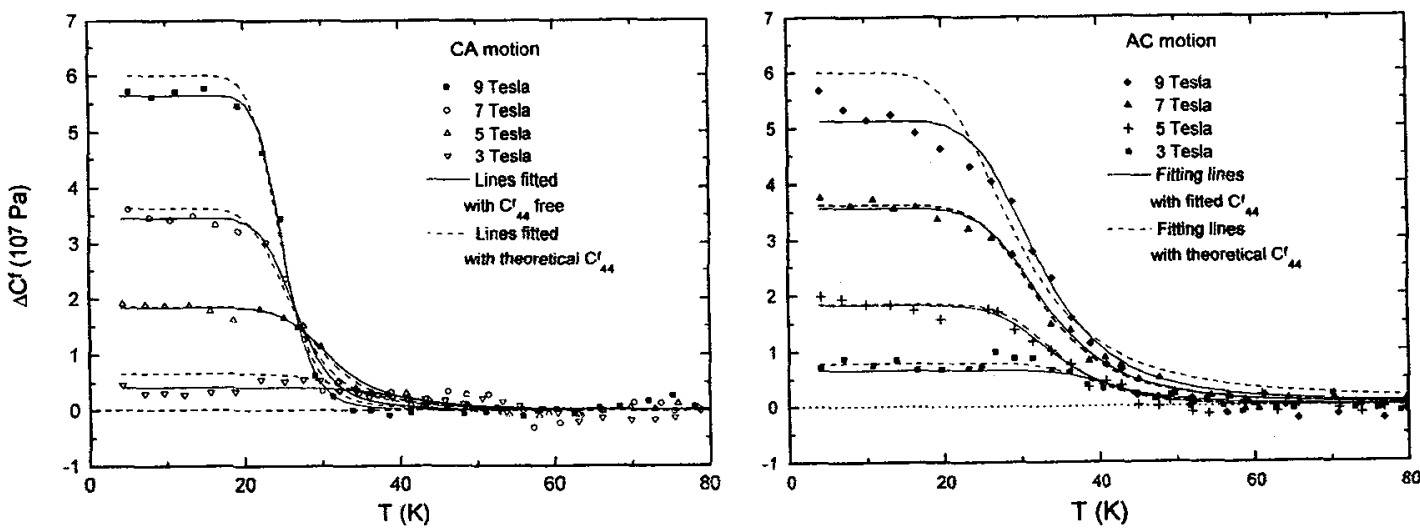

Figure 2. Temperature dependences magnetic field dependent elastic modulus $\Delta \mathrm{c}_{44}{ }^{\mathrm{f}}$ obtained from (a) $\mathrm{CA}$ and (b) AC mode data, fitted by the Pankert [1] expressions, as discussed in the text.
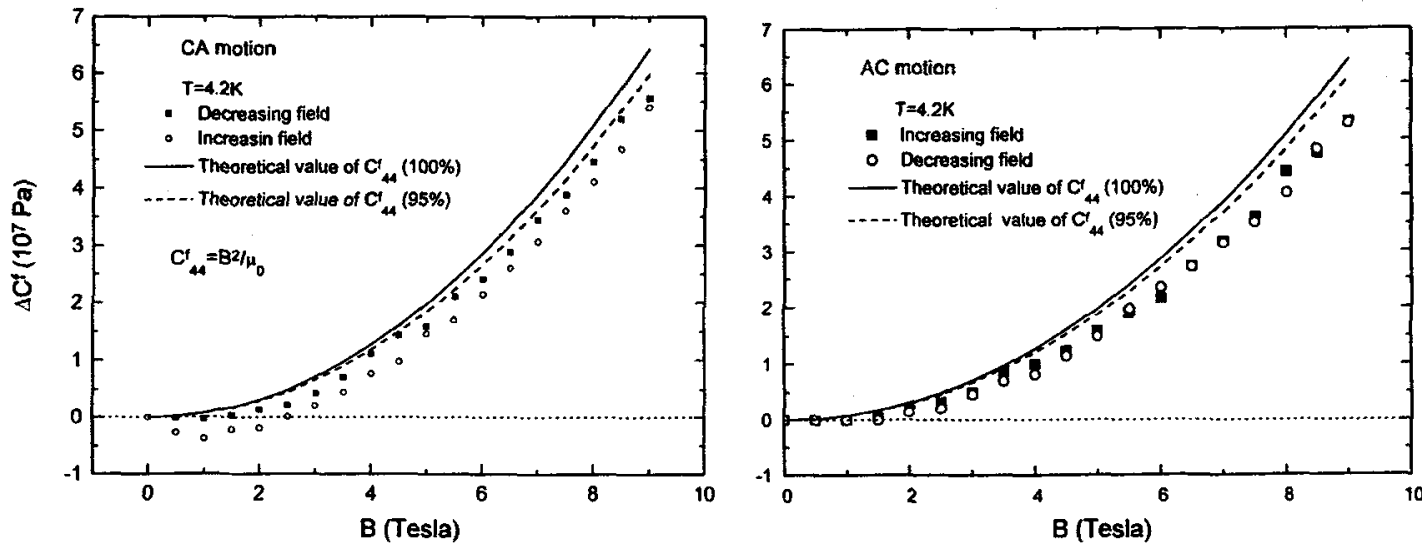

Figure 3. Magnetic field dependences of $\Delta \mathrm{c}_{44}{ }^{\mathrm{f}}$ measured at $4.2 \mathrm{~K}$ caused by (a) $\mathrm{CA}$ mode and (b) AC mode interaction with the FLL in $\mathrm{Bi}_{2} \mathrm{Sr}_{2} \mathrm{CaCu}_{2} \mathrm{O}_{8+\mathrm{y}}$, compared with fully pinned FLL predictions. 
The magnetic field dependence of $\Delta \mathrm{c}_{44}{ }^{\mathrm{f}}$ for (a) the CA mode and (b) the AC mode, measured at $4.2 \mathrm{~K}$, are shown in Figure 3, compared with the density corrected theoretical values, equation 1 . The values of the FLL pinning potential employed in the various fittings are shown in Table 1.

\begin{tabular}{|c|c|c|c|c|}
\hline $\mathrm{B}$ (tesla) & $\mathrm{AC}$ (sample 1) & $\mathrm{AB}$ (sample 1) & $\mathrm{CA}$ (sample 1) & $\mathrm{CA}$ (sample 2) \\
\hline 9 & $114 \pm 12$ & $113 \pm 26$ & $8.5 \pm 0.9$ & $189 \pm 14$ \\
\hline 7 & $121 \pm 9$ & $62 \pm 13$ & $9.1 \pm 1.1$ & $151 \pm 19$ \\
\hline 5 & $155 \pm 20$ & - & - & $136 \pm 14$ \\
\hline 3 & $210 \pm 60$ & - & - & $184 \pm 90$ \\
\hline
\end{tabular}

Table 1, FLL pinning activation energies (units deg. $\mathrm{K}$ ) in $\mathrm{Bi}_{2} \mathrm{Sr}_{2} \mathrm{CaCu}_{2} \mathrm{O}_{8+\mathrm{y}}$ obtained by fitting the Pankert model [1] to velocity data obtained for the $\mathrm{AC}, \mathrm{AB}$ and $\mathrm{CA}$ modal configurations.

\section{CONCLUSIONS}

The experimental data obtained from the two highly textured samples of $\mathrm{Bi}_{2} \mathrm{Sr}_{2} \mathrm{CaCl}_{2} \mathrm{O}_{8+y}$ are in good agreement with the Pankert model based on thermally assisted flux flow. The magnitudes of the elastic stiffening at lowest temperatures are remarkably close to the theoretical predictions, for a fully pinned FLL. It is noteworthy that both CA mode (sample 2) and AC mode data shows an equally fully pinned FLL, indicating an abundance of extrinsic pinning centres for CA mode to match the intrinsic pinning centres available for $\mathrm{AC}$ mode.

A very large difference was found between the $\mathrm{CA}$ mode data obtained in the two samples indicating a sample shape/size effect. The data from the large second sample showed excellent agreement with the theoretical model. The fit for this sample was also superior to that obtained for $A C$ and $A B$ from sample 1. The implication of this is that these data were also affected, to a smaller extent, by a sample shape/size effect, despite $3 \times 5 \mathrm{~mm}$ faces being exposed to the magnetic field. If this is the case, concern must be expressed about the interpretation of data obtained by other techniques from small single crystal samples.

The curve fitting values of the activation energy of pinning, Table 1, cover a fairly small range. There appears to be a small difference between AC (intrinsically pinned) and CA (extrinsically pinned) modes. However, this is not conclusive in view of the above observation concerning the differences in sample size and shape. There is little evidence of a pinning activation energy magnetic field dependence .

The overall picture that has emerged from this work is that the FLL produced in textured polycrystalline $\mathrm{Bi}_{2} \mathrm{Sr}_{2} \mathrm{CaCu}_{2} \mathrm{O}_{8+y}$ can be characterised by the TAFF model using a pinning potential of about $160 \mathrm{~K}$, and that there are sufficient pinning centres to pin fully the lattice at lowest temperatures, irrespective of field orientation.

\section{Acknowledgements}

The authors are grateful to the Engineering and Physical Science Research Council for their support.

\section{References}

[1] Pankert, J. Physica C168 (1990) 335-345.

[2] Pankert, J, Marbach, G, Comberg, A, Lemmens, P, Froning and P, Ewert. Phys.Rev.Lett. 65 (1990) 3052-55.

[3] Hanaguri, T, Fukase, T, Tanaka, I and Kojima, H. Phys.Rev.B48 (1993) 9772-80.

[4] Saunders, G.A., Fanggao, C, Jiaqiang, L, Wang, Q, Cankurtaran,M, Lambson, E.F, Ford, P.J and Almond, D.P. Phys.Rev.B49 (1994) 9862-73.

[5] Kes, P.H, Aarts, J, van den Berg, J, van der Beek, C.J and Mydosh, J.A.

Supercond. Sci.Technol. 1 (1989) 242-248.

[6]Tachiki, M and Takahashi, S. Solid State Commun. 70 (1989) 291-294. 